\title{
Geometrical Optimisation of Transpired Solar Collectors Using Design of Experiments and Computational Fluid Dynamics
}

\author{
Sadjad Tajdaran ${ }^{\mathrm{a},}$, Christopher Kendrick $^{\mathrm{a}}$, Edward Hopkins ${ }^{\mathrm{a}}$, Fabrizio Bonatesta $^{\mathrm{a}}$ \\ ${ }^{a}$ Oxford Brookes University, Gipsy Lane, Oxford OX3 OBP, UK
}

\begin{abstract}
Transpired Solar Collectors (TSCs) are simple low maintenance air heating systems which have been widely used for agricultural and industrial applications. In spite of their potential, these systems have not been yet widely employed in residential buildings as they are unable to generate high grade heat for moderate and low ventilation demands. Hence there is an opportunity for optimisation studies in order to enhance the thermal performance of these systems.

Optimisation and parametric studies can be costly and time consuming if carried out by physical experiments. CFD models however offer a more flexible and less expensive tool to carry out such studies. This research has aimed to optimise the geometry of the solar absorber plate using a validated CFD model which accounts for a wide range of the key factors affecting TSC performance.

A $2^{\text {nd }}$ order polynomial predictive model was developed based on the CFD results with Root Mean Squared Error (RMSE) of 3.8\%. The predictive model was used to identify an optimal geometry which delivers a Heat Exchange Effectiveness (HEE) of 0.739 . The optimised geometry demonstrated $43 \%$ increase in HEE whilst using $28 \%$ less material compared to the baseline geometry under the same operating conditions. This geometry can be integrated with other performance enhancement techniques to further improve the thermal performance of TSCs.
\end{abstract}

Keywords: Transpired solar collectors; Computational Fluid Dynamics; Optimisation

\section{Introduction}

\subsection{Brief Background on Transpired Solar Collectors}

Transpired Solar Collectors (TSCs) are amongst the technologies which have been developed as an alternative for conventional heating systems. These systems were originally developed in Canada for summer crop-drying, but as a consequence of design optimisation can now be used to supplement building space heating in temperate climates by providing useful amounts of warm air in the Autumn and Spring (Hollick, 1994). TSCs are typically able to deliver air $10-15^{\circ} \mathrm{C}$ warmer than ambient external temperature (Hall et al. 2014). This warm air can either be ducted directly into buildings or be used as preheat for 'Heating, Ventilation and Air Conditioning' (HVAC) systems (Athienitis et al., 2011).

The system is comprised of a micro-perforated steel sheet mounted on a building façade together with a ventilation fan drawing ambient outside air through the perforations (Figure 1). The micro-perforated steel sheet acts as a solar absorber plate which then transfers heat to the ambient air layer next to its surface. The heated air gains more heat as it passes through the perforations and streams along the back surface of the absorber plate within the cavity behind the plate as it is drawn in via the ventilation fan. The heated air is then ducted into a building as a warm air supply.

\footnotetext{
* Corresponding author. Tel.:+44-1865-484086.

E-mail address: stajdaran@brookes.ac.uk
} 


\begin{tabular}{|c|c|c|c|}
\hline \multicolumn{4}{|c|}{ Nomenclature } \\
\hline$D$ & hole diameter (mm) & $V_{i n}$ & systems' inlet air velocity $(\mathrm{m} / \mathrm{s})$ \\
\hline I & solar radiation intensity $\left(\mathrm{W} / \mathrm{m}^{2}\right)$ & $V_{\text {out }}$ & systems' outlet air velocity $(\mathrm{m} / \mathrm{s})$ \\
\hline$\dot{m}$ & mass flow rate $(\mathrm{kg})$ & $V_{S}$ & suction velocity $(\mathrm{m} / \mathrm{s})$ \\
\hline$p$ & pressure $(\mathrm{Pa})$ & $\dot{W}_{\text {flow }}$ & rate of flow work $\left(\mathrm{W} / \mathrm{m}^{2}\right)$ \\
\hline$P$ & pitch (mm) & & \\
\hline$Q_{\text {gain }}$ & gained heat of the system $\left(\mathrm{W} / \mathrm{m}^{2}\right)$ & \multicolumn{2}{|l|}{ Greek symbols } \\
\hline$R e_{b}$ & $\begin{array}{l}\text { Reynolds number based on pitch } \\
\text { and velocity in the hole }\end{array}$ & $\alpha$ & absorptivity \\
\hline$R e_{h}$ & $\begin{array}{l}\text { Reynolds number based on diameter } \\
\text { and velocity in the hole }\end{array}$ & $\Delta h$ & height variation $(\mathrm{m})$ \\
\hline$R e_{s}$ & $\begin{array}{l}\text { Reynolds number based on pitch } \\
\text { and suction velocity }\end{array}$ & $\varepsilon$ & TSCs heat exchange effectiveness \\
\hline$R e_{w}$ & $\begin{array}{l}\text { Reynolds number based on pitch } \\
\text { and wind speed }\end{array}$ & $\varepsilon_{\text {back }}$ & $\begin{array}{l}\text { heat exchange effectiveness contribution by } \\
\text { the back surface of the absorber }\end{array}$ \\
\hline$t$ & plate thickness $(\mathrm{mm})$ & $\varepsilon_{\text {front }}$ & $\begin{array}{l}\text { heat exchange effectiveness contribution by } \\
\text { the front surface of the absorber }\end{array}$ \\
\hline$T_{a m b}$ & ambient temperature $\left({ }^{\circ} \mathrm{C}\right)$ & $\varepsilon_{\text {perf }}$ & $\begin{array}{l}\text { heat exchange effectiveness contribution by } \\
\text { the perforations }\end{array}$ \\
\hline$T_{p i}$ & perforations inlet temperature $\left({ }^{\circ} \mathrm{C}\right)$ & $v$ & specific volume $\left(\mathrm{m}^{3} / \mathrm{kg}\right)$ \\
\hline$T_{p o}$ & perforations outlet temperature $\left({ }^{\circ} \mathrm{C}\right)$ & Abbreviation & \\
\hline$T_{\text {out }}$ & outlet temperature of system $\left({ }^{\circ} \mathrm{C}\right)$ & PRESS & Prediction Error Sum Of Squares \\
\hline$T_{S}$ & absorber surface temperature & RMSE & Root Mean Squared Error \\
\hline$U_{w}$ & wind speed $(\mathrm{m} / \mathrm{s})$ & TSCs & Transpired Solar Collectors \\
\hline
\end{tabular}

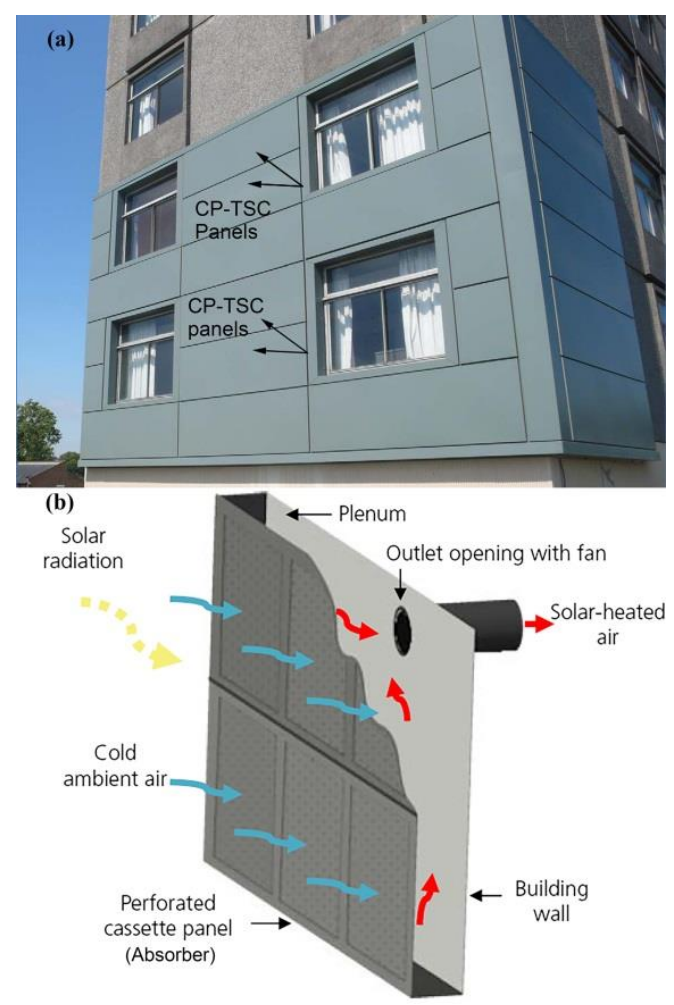

Figure 1. (a) Building façade with the installed cassette-panels (the perforated panels are the four panels directly between the windows), (b) Conceptual illustration of a Cassette Panel-TSC solar air-heating system (Hall et al., 2014). 
Whilst the literature shows an overall agreement on some key parameters which affect the thermal performance of the system, other parameters have routinely been regarded as negligible or excluded from the investigations. Here is a summary of the effective parameters which have been discussed in the literature:

\section{- Geometry}

- Perforations diameter and pitch distance; these two parameters have been widely recognised as amongst the most important affecting TSC performance (Kutscher, 1992; Leon and Kumar, 2007)

- Plate thickness; generally overlooked, it has been recognised by some studies as having a nonnegligible effect on either the thermal or the mechanical performance of systems (Gunnewiek et al., 1996; Arulanandam, 1999; Van Decker et al, 2001).

- Types of heat transfer; all three forms of heat transfer, namely radiation, conduction and convection, have been recognised to have significant contribution towards the thermal performance of TSCs however have not been consistently respected due to simplifying assumptions and resource limitations (Van Decker et al., 2001; Tajdaran et al., 2015).

- Thermo-physical properties; Arulanandam et al. (1999) and Golneshan et al., (1994) addressed the role of thermal conductivity of the absorber plate on the performance of TSCs. The effect of emissivity of the plate coating was discussed in Leon and d Kumar (2007). Hall et al. (2016) have demonstrated the benefit of the low-emissivity absorber plate within the infrared wave length range.

- Suction and wind velocity; depending on the level of suction through the perforations, which is normally originated by means of a fan located at the top of system within the plenum, suction uniformity varies across the system (Gunnewiek et al., 1996). However, a number of studies have considered suction to be homogenous through perforations (Wan et al., 2017, Arulanandam et al., 1999). In most cases wind velocity has been considered as parallel to the absorber plate, and laminar, leading to a limited account of the realistic climatic conditions and system operation (Fleck et al., 2002)

A great body of research has been carried out about TSCs, which includes laboratory and in-site experiments as well as mathematical and CFD modelling. Whilst this has led to an improved understanding of TSCs thermal performance, significant knowledge gaps and limitations in the available literature can still be identified:

- Asymptotic boundary layer to take place over the perforated absorber plate. This assumption has been applied in few TSC studies (Kutscher, 1992; Gunnewiek et al., 1996; Gawlik and Kutscher, 2002;). This assumption requires air suction through the perforations to respect a minimum value of suction mass flow rate whilst the approaching airflow is uniform and laminar (Shclichting, 1979). The assumption of an asymptotic boundary layer simplifies the numerical analysis with the same flow behaviour around the perforations which reduces the computational power demand significantly (Leon and Kumar, 2007; Collins and Abulkhair, 2014).

- Not all types of heat transfer have consistently been taken into account evaluating the thermal performance of TSCs. Abulkhair and Collins (2010) assumed convective heat loss as negligible. Solar radiation was applied by a heat flux boundary condition in the work of Li et al. (2013). Arulanandam et al. (1999) assumed the back of the plate to be adiabatic so no heat convection could take place along that part of the absorber.

- Routinely adopted simplifications and limiting assumptions, e.g. homogenous uniform suction, laminar airflow, parallel wind flow, exclusion of convective and/or radiative heat loss sources (Kutscher, 1992; Arulanandam et al., 1999; Van Decker et al., 2001; Li et al., 2013).

- Limited account of both the thermal and airflow fields simultaneously, leading to the noncomprehensive replication of the complexities of realistic TSC operation (Golneshan, 1994; Fleck et al, 2002; Biona et al., 2005; Hall et al., 2014). 


\section{2. $\quad$ Existing Predictive correlations}

A typical TSC system operates under non-uniform suction conditions together with turbulent surrounding flow blowing against the absorber plate at different angles (Li t al., 2013; Hall et al., 2014). The developed predictive correlations for TSCs thermal performance however are based on assumptions that lack a comprehensive representation of realistic operating conditions.

Heat Exchanger Effectiveness (HEE) is defined as the ability of heat exchangers to deliver output temperature compared to their corresponding input temperature. HEE for TSCs is calculated as:

$\varepsilon=\frac{\left(T_{o u t}-T_{a m b}\right)}{\left(T_{s}-T_{a m b}\right)}$

where, $T_{a m b}$ is the ambient temperature, $T_{\text {out }}$ outlet temperature and $T_{s}$ is the absorber surface temperature.

The thermal efficiency of TSCs is calculated as the ratio of the heat transferred to the air through the system to the total solar energy that falls on the TSC surface:

$\eta=\frac{\dot{m} c_{p}\left(T_{o u t}-T_{a m b}\right)}{I A_{s}}$

where, $I$ is solar heat flux and $A_{s}$ is collector surface area. Having $T_{s}$ and heat exchange effectiveness determined, the thermal efficiency can also be defined as (Kutscher, 1992):

$\eta=\frac{\rho c_{p} \varepsilon V_{s}\left(T_{c o l l}-T_{a m b}\right)}{I}$

A correlation was developed for Heat Exchange Effectiveness by Kutscher (1992) based on work on heat transfer mechanisms in TSC systems. Experiments were carried out for plates with the porosity of $0.1 \%$ to $5 \%$ and the wind speed variation was from 0 to $4 \mathrm{~m} / \mathrm{s}$. The study was based on the homogenous suction theory of Schlichting (1979), assuming that the airflow approaching the perforated plate is laminar and a specified level of homogenous suction through the perforations maintains the laminar flow regime streaming over the plate. The thickness of the boundary layer over the perforated plate was assumed to be constant indicating that no heat or mass exchange takes place with the boundary layer.

Arulanandam et al. (1999) extended Kutscher's study over a wider range of operating parameters and developed a CFD model to derive an equation for HEE of TSCs under no-wind conditions. Using the asymptotic boundary layer hypothesis, the model was created for a quarter of a single perforation. Simulations were run over a range of non-dimensional parameters and a correlation was then found between HEE and the suction velocity and the plate geometry. The study demonstrated that with some modification in design, acceptable efficiency levels can be achieved even for low conductivity absorbers.

Van Decker et al. (2001) also extended Kutscher's work to a wider range of plate thickness, pitch distance, suction velocities and square pitch layout of perforations, with the aim of developing a predictive HEE model. Experiments were performed for nine different plate geometries under both wind and no-wind conditions, assuming uniform flow suction through the perforations and negligible convective heat loss (Kutscher, 1992). HEE correlations were developed separately for the main parts at which heat transfer takes place, comprising front and back surface of the plate and perforations. These were then combined together into a single HEE correlation, which remains valid within the limits of a specified range of geometry configurations and operating conditions: 
$\varepsilon=\left[1-\left(1+R e_{s} \max \left[1.733 R e_{w}{ }^{-0.5}, 0.02136\right]\right)^{-1}\right] \times\left[1-\left(1+0.2273 R e_{b}^{0.5}\right)^{-1} \times\right.$

$\exp \left(-0.01895 \frac{P}{D}-\frac{20.62 t}{R e_{h} D}\right)$

For typical operating conditions, the contribution of each part to the overall temperature rise was estimated to be about $62 \%$ on the front surface, $28 \%$ within the perforations, and $10 \%$ at the back of the plate. It was noted that in contrast with Kutscher's study, heat transfer in perforations was found to make a considerable contribution to the overall heat transfer.

Badache et al. (2012) employed a Design of Experiments (DoE) approach performing laboratory tests to develop a second order polynomial correlation for thermal efficiency (Eq. 3). The variable factors were hole diameter, absorber coating represented by absorptivity $(\alpha)$, solar radiation $(I)$ and mass flow rate $(\dot{m})$. It was found that the thermal efficiency $(\eta)$ is mostly dominated by absorber coating characteristics and mass flow rate, whilst the influence of hole diameter is insignificant.

$\eta=66.5+22.42 \alpha-4.29 I+18.37 \dot{m}-25.67 \alpha^{2}-2.93 \alpha I+11.3 \alpha \dot{m}-3.92 \dot{m}^{2}$

Eq. 5

Tajdaran et al. (2016) developed a comprehensive CFD model of a typical TSC system, which accounts for the influence of a range of key performance parameters. The model is based on a system mounted on a building at Oxford Brookes University (latitude $51.75^{\circ}$, longitude $-1.13^{\circ}$ ), and operated under realistic conditions (Hall et al., 2014). An ample validation exercise against experimental data demonstrated acceptable accuracy, proving the model can be used as a reference for further parametric study and optimisation analysis.

This validated CFD model has been used in the current study for geometry optimisation using a DoE approach. The main aim of the work has been to enhance the TSC performance in terms of its ability to generate a relatively higher grade heat. The developed methodology is robust and sufficiently versatile to accommodate reasonably wide ranges of climatic and geometric conditions. It has also been tried to demonstrate the role of pressure drop on the system's performance and its relation to the geometrical optimisation.

In what follows, in Section 2 presents the brief numerical model description and the methodology of the optimisation study whilst also demonstrating the importance of pressure drop across the TSC system providing a reference for discussion in the following sections. Section 3 presents the results and discussion of the optimisation study and it implications and finally Section 4 presents the conclusions.

\section{Methodology}

\subsection{Model Description}

The multi-scale physics and turbulent fluid flow in and around a TSC system have been simulated using the commercially available CFD software package STAR-CCM+. The approach has been to solve steady-state, three-dimensional Reynolds Averaged Navier-Stokes (RANS) equations, together with Realizable $k-\varepsilon$ turbulence closure model, over a suitably high resolution computational domain. A high resolution grid, in particular, is necessary in regions of high gradients i.e. boundary layer adjacent to the absorber plate and the jet flows emerging from the perforations. The grid and the corresponding boundary conditions have been developed in a way to appropriately capture the main physical phenomena, as a result of variations in relevant performance parameters including wind speed $\left(U_{w}\right)$ and direction, suction ratio $\left(V_{s} / U_{w}\right)$, thermo-physical properties of the absorber plate, sun position and solar radiation intensity $(I)$, turbulent flow and non-uniform suction. The CFD model is discussed in details in Tajdaran et al. (2015). The temperature outputs, pressure distribution across the TSC, and the corresponding Heat Exchange Effusiveness (HEE) previously predicted by the CFD analysis in Tajdaran et al. (2016) will be used in the following sections to demonstrate the impact of the geometry optimisation in the current study. 


\subsection{Geometry Optimisation}

Once available data is sufficiently wide-ranging and representative of its operation, model-based optimisation is an effective methodology to drive optimal design of a real system (Montgomery, 2012). In the present work, the approach is used to identify an optimised combination of absorber plate geometrical variables which delivers the highest possible heat exchanger effectiveness.

Figure 2 shows the factors of interest which include pitch distance (P), perforation diameter (D) and absorber thickness $(\mathrm{t})$. The single objective of the model-based optimisation is to maximise HEE. The ranges of variability for the three factors are:

- $\quad 0.8 \mathrm{~mm} \leq D \leq 3.2 \mathrm{~mm}$

- $7 \mathrm{~mm} \leq P \leq 23.33 \mathrm{~mm}$

- $0.7 \mathrm{~mm} \leq t \leq 1.2 \mathrm{~mm}$

These range of variability is decided based on the practical values reported in the literature (Van Decker et al., 2001; Leon and Kumar, 2007);

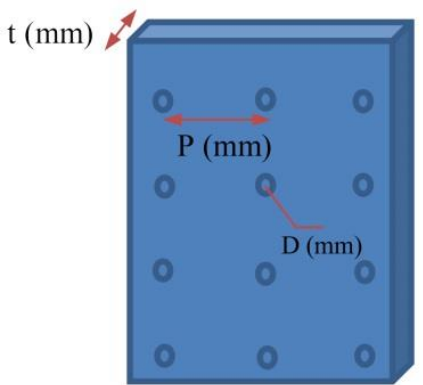

Figure 2. Schematic illustration of absorber geometry

Other factors that may exert an influence on the 'responses' of the optimisation study are held as constant. 'Held-constant factors' are shown in Table 1, and they are given values representative of average TSCs operation according to literature and industry reference values. As shown in the Results section, the generality of the optimisation exercise, i.e. the optimised TSC geometry, was subsequently assessed and validated against a realistic range of operational parameters.

Table 1. Held-constant factors for geometrical optimisation

\begin{tabular}{cccccc}
\hline $\begin{array}{c}\text { Ambient Air } \\
\begin{array}{c}\text { Temperature } \\
\left({ }^{\circ} \mathrm{C}\right)\end{array}\end{array}$ & $\begin{array}{c}\text { Wind } \\
\text { Speed } \\
(\mathrm{m} / \mathrm{s})\end{array}$ & $\begin{array}{c}\text { Wind } \\
\text { Direction }\end{array}$ & $\begin{array}{c}\text { Suction } \\
\text { Ratio }\end{array}$ & $\begin{array}{c}\text { Solar } \\
\text { Radiation } \\
\left(\mathrm{W} / \mathrm{m}^{2}\right)\end{array}$ & $\begin{array}{c}\text { Mass Flow } \\
\text { Rate }(\mathrm{kg} / \mathrm{s})\end{array}$ \\
\hline 10 & 5 & 0 & 0.008 & 600 & 0.01238 \\
\hline
\end{tabular}

A series of different combinations within the specified ranges of the factors of interest must be considered for optimisation. Importantly, this series must be a representative and statistically relevant sample or population (Garud et al., 2017). Design of Experiments has been employed for this purpose. DoE is a statistical approach to plan experiments (or, in the present case, simulation runs) in a way to capture the effects of multiple relevant variables and their potential interaction. The use of DoE facilitates appropriate data collection as well as data analysis to determine the impact of each variable on the output response. The analysis has been performed using the Model-Based Calibration (MBC) toolbox of MATLAB. The foptcon algorithm has been used for the single objective multi-variable optimisation study. foptcon is a modified version of fmincon from the MATLAB 
Optimisation Toolbox ${ }^{\mathrm{TM}}$, which is suitable to find minima and maxima of constrained non-linear multi-variation functions (MBC User's Guide, MATLAB \& SIMULINK R2017a).

Halton sequence space-filling design has been employed to develop the DoE in the present work. Space filling is a replication-free sampling approach which is suitable for computer models in which the response variables are mathematically calculated and free from signal noise (Montgomery, 2012). Halton is a low discrepancy quasi-random sequence which benefits from both the feature of randomised sampling and a lattice that ensures design points do not clump together and evenly cover the whole region of interest. Figure 3 depicts the main DoE browser panel in Matlab, which includes a 3D preview of the geometrical combinations to simulate within the pre-determinate Pitch-Diameter-Thickness space envelope. The initial DoE featured 22 points to which another eight corner points were added to cover the whole design space. The total population size of 30 training points enabled capturing the third order factor interactions, using up to forth order polynomial regression models. As reported in the results section below, the simulation database was subsequently enlarged to increase accuracy as well as to better capture the responses in one specific corner of the space envelope.

Once all the simulations are completed, the output data are used to perform the analysis. The general approach was to use CFD-evaluated HEE values to develop a predictive model correlating with the factors of interest, using different regression models. Polynomial models of second, third and fourth order have been chosen for data regression analysis. It is important to assess if the predictive model is able to represent the general and realistic behaviour of the system. Moreover, four statistical measures have been use to assess the quality of each polynomial fitting model which are:

- RMSE; the Root Mean Squared Error (RMSE) calculates the distance (i.e. the error) between the actual points to the regression line which quantifies the quality of the distribution of the points around the regression line.

- $\quad$ PRESS; Predicted Residual Error Sum of Squares (PRESS) is a measure of predictive power of statistical models.

- $\quad$ R-squared; it states what percentage of the response variation is predicted by the independent variables.

- Adjusted R-squared; it gives the percentages of variation explained by the parameters that actually matter

The results concerning the quality of the regression models are presented below in the Results and Discussion Chapter. 


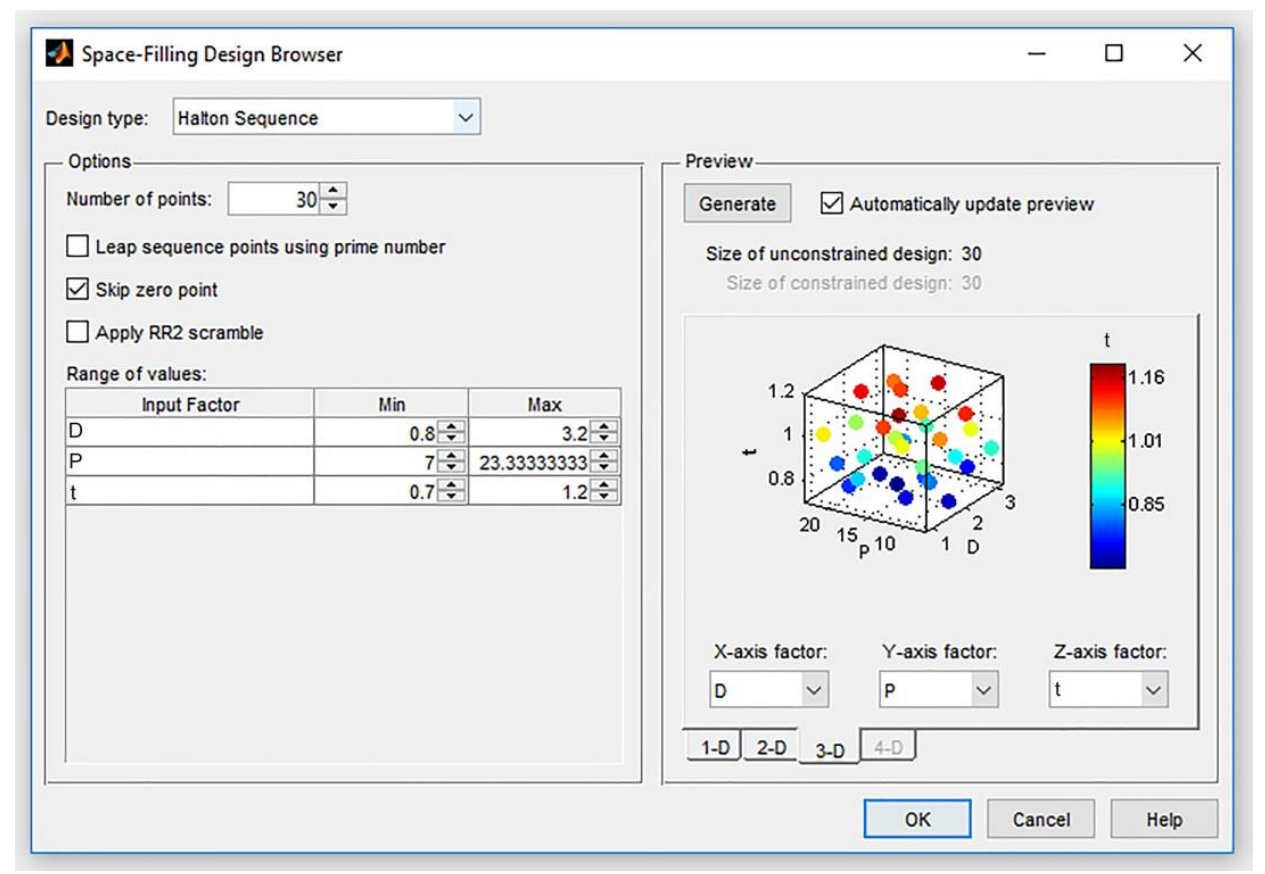

Figure 3. An image of the main DoE browser panel in MATLAB.

\subsection{Impact of Pressure Drop}

The analysis previously reported in Tajdaran et al. (2016) is extended here to further explore the influence of system pressure drop on thermal performance. This is highly relevant to the present investigation because system geometry modifications affect the absorber plate porosity and, in turn, may exert a significant impact on pressure drop. Figure 5(a), which collates results from Tajdaran el al. (2016) for the default TSC geometry (Tajdaran et al., 2015, Hall et al., 2014) shows how the pressure drop across the system increases with increasing wind speed, and how for speed in excess of $3 \mathrm{~m} / \mathrm{s}$ this correlation becomes increasingly stronger as suction ratio increases. Correspondingly, Figure 5(b) shows how HEE decreases with increasing wind speed and suction ratio. Figures 5 (a) and (b) clearly suggest the existence of an inverse relationship between pressure drop and Heat Exchange Effectiveness (HEE) of the system. Such relationship is in agreement with the research carried out by Dymond and Kutscher (1997) and Gunnewiek et al. (2002), which outline the importance of pressure drop on system thermal performance. On one hand, higher suction ratios support forced convection in the inner part of the system, which may help delivering a higher amount of heat into the system; on the other hand, they produce relatively cooler air and subsequently smaller HEE values compared to the lower suction rates (Wang et al., 2017; Leon et al., 2007).
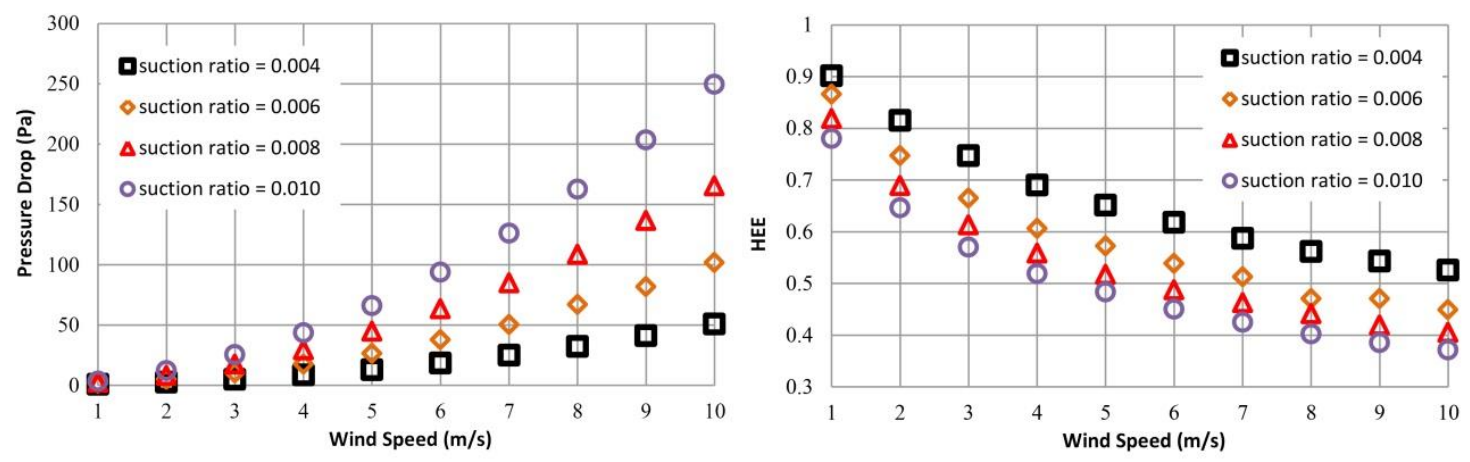
Figure 4. Impact of wind speed and suction ratio on the Heat Exchange Effectiveness and the pressure drop across the system $\left(p_{\text {out }}-p_{\text {in }}\right)$

\section{Results and Discussion}

\subsection{Geometry optimisation}

The original DoE database incorporated 30 different geometrical configurations as reported in the Methodology section (Figure 5). These various configurations have been modelled using the validated CFD model and the predicted performance have been used for the optimisation purpose. The analysis performed using this initial set showed that the optimal solution would lie around one corner - indicated as point A in Figure 5, irrespective of the regression model used while a single unique combination of pitch, diameter and thickness was not achieved. This result however is in agreement with Van Decker et al. (2001) and Leon et al (2007) which show how the highest values of HEE correspond to the lowest levels of pitch and hole diameter. To the author's best knowledge, no geometrical optimisation studies have been carried out which consider the combined effect of hole diameter, pitch distance as well as absorber plate thickness.

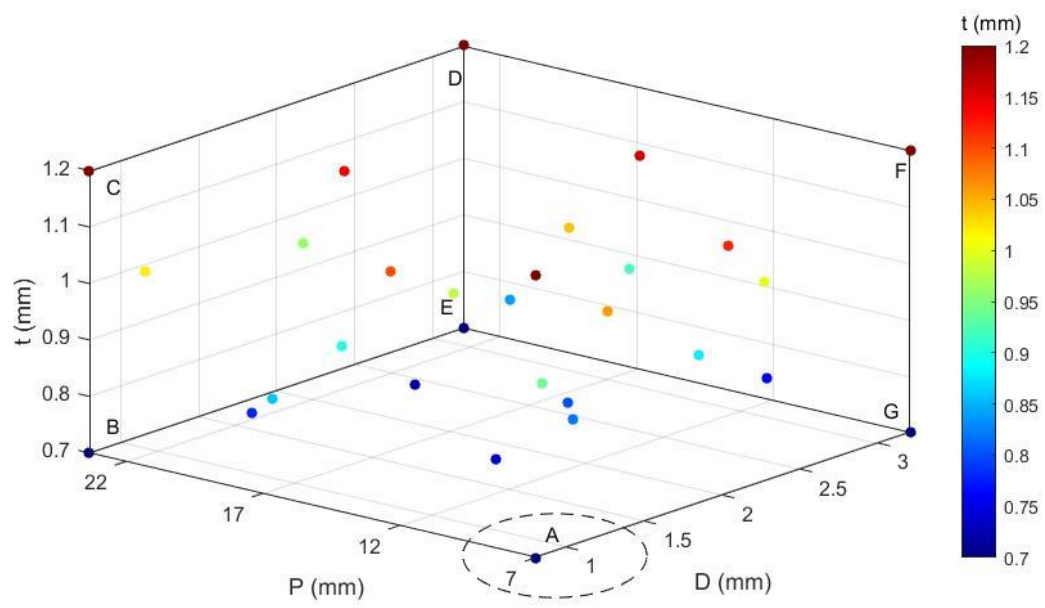

Figure 5. 3D view of the initial DoE database within the Diameter-Pitch-Thickness space envelope

In order to obtain increased accuracy around the initial solution (Point A, Figure 5), 12 extra points/geometrical configurations have been added to the original database and simulated; nine clustering around corner A, plus another three further way from corner A (Figure 6). The away points were added to the training population due to the inconsistent behaviour of HEE regression curve at those areas. 


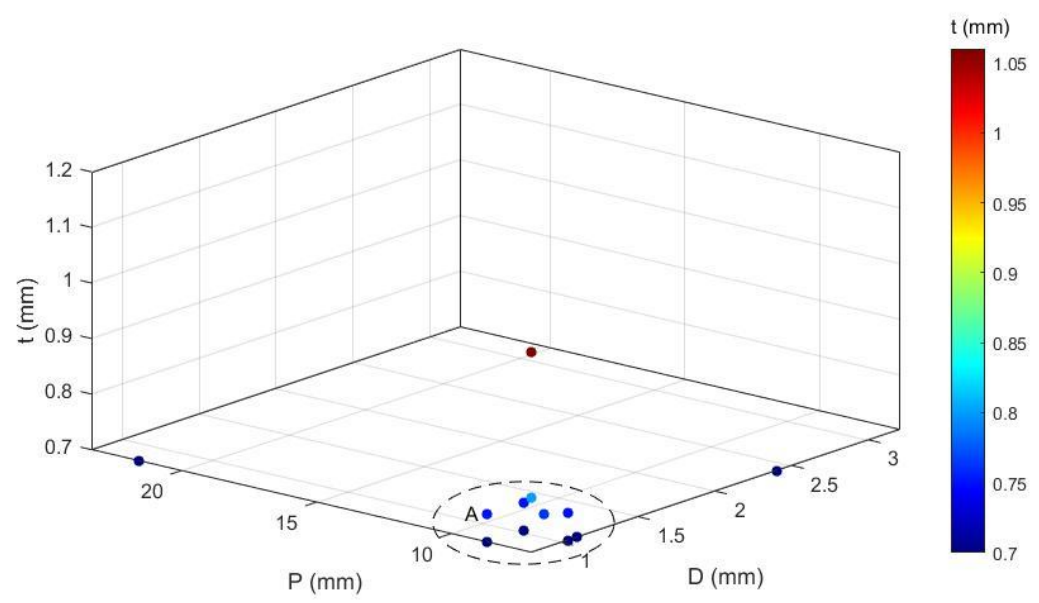

Figure 6. Details of the extra 12 points added to the initial DoE database

The optimal solutions produced based on the 42 training points summarised in Table 2.

Table 2. Optimal solutions for the geometrical factors of interest returned by different regression models.

\begin{tabular}{ccccc}
\hline Regression Model & HEE & $\mathrm{D}(\mathrm{mm})$ & $\mathrm{P}(\mathrm{mm})$ & $\mathrm{t}(\mathrm{mm})$ \\
\hline Polynomial of $2^{\text {nd }}$ order & 0.739 & 0.8 & 7.0 & 0.866 \\
$3^{\text {rd }}$ order & 0.741 & 0.8 & 7.0 & 0.927 \\
$4^{\text {th }}$ order & 0.754 & 0.8 & 7.0 & 0.761 \\
\hline
\end{tabular}

Figure 7 shows the HEE response lines obtained for the three regression models used, respectively $2^{\text {nd }}, 3^{\text {rd }}$ and $4^{\text {th }}$ order polynomial. Each response line is obtained by fixing two factors of interest at their optimal level and allowing the remaining one to vary within its interval of variability. With the increased sample population size of 42, all regression models in Figure 7 show consistent results for optimal pitch size and hole diameter. The absorber plate thickness has not been resolved into a single solution, with the optimal value between 0.76 and $0.93 \mathrm{~mm}$ depending on the regression model used. However, the associated HEE variation is limited to two points percent, between 75 and $77 \%$. The quality of the regression models is expressed in terms of R-squared, R-squared adjusted, RMSE and PRESS. These factors are reported in Table 3. 


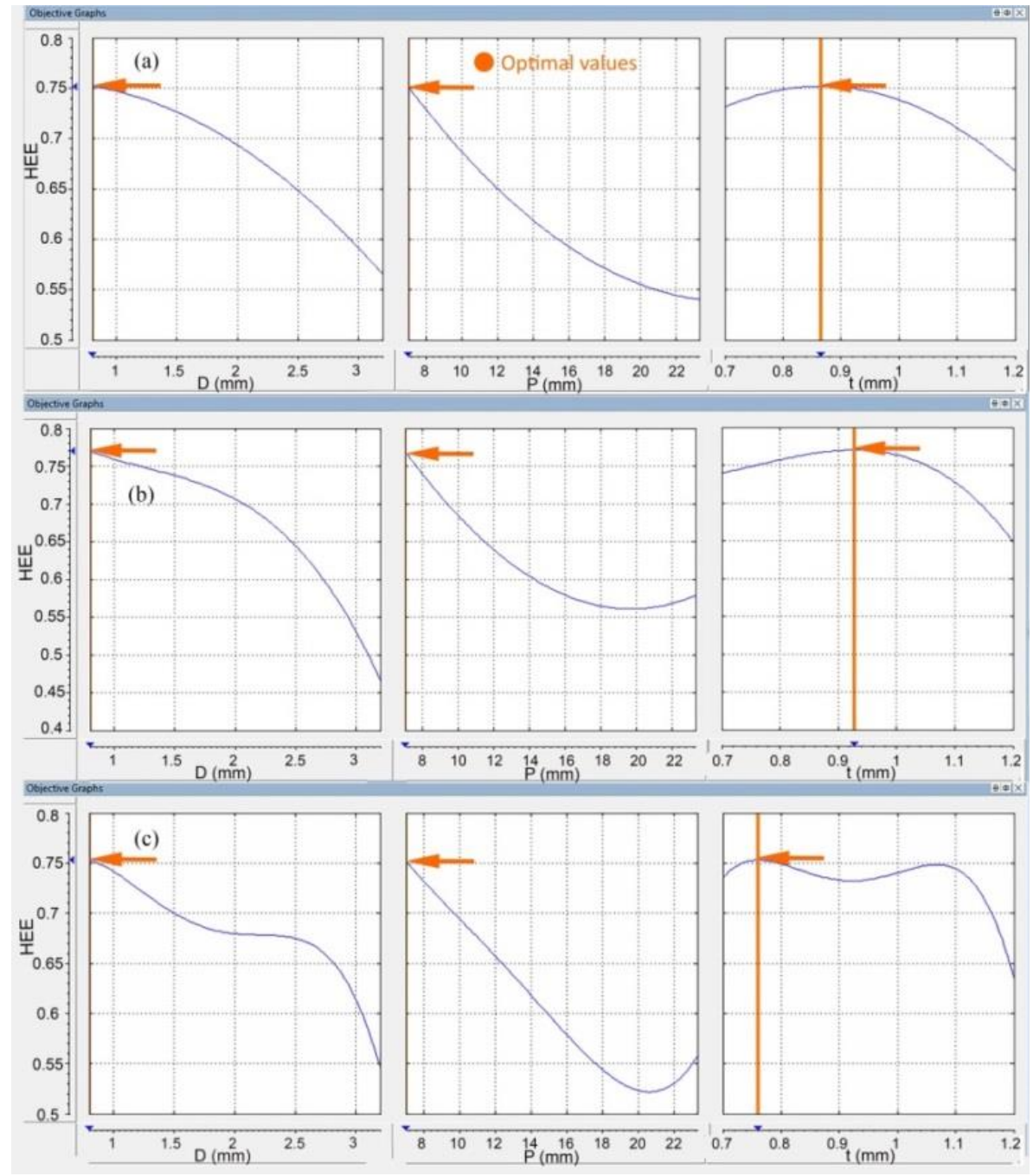

Figure 7. Distribution of optimal HEE levels as a function of individual design parameters: (a) $2^{\text {nd }}$ order regression model, (b) $3^{\text {rd }}$ order model, (c) $4^{\text {th }}$ order model, for a sample population size of 42 .

Table 3. Quality indicators of the regression models

\begin{tabular}{ccccc}
\hline Regression Model & RMSE & PRESS & $\boldsymbol{R}^{\mathbf{2}}$ & $\boldsymbol{R}_{\boldsymbol{a d j}}^{2}$ \\
\hline Polynomial of $2^{\text {nd }}$ order & 0.038 & 0.06 & 0.875 & 0.86 \\
$3^{\text {rd }}$ order & 0.032 & 0.0054 & 0.92 & 0.91 \\
$4^{\text {th }}$ order & 0.029 & 0.0051 & 0.94 & 0.94 \\
\hline
\end{tabular}

The analysis of Figure 8 reveals that increasing the sample population size has not cured the presence of fluctuations and turning points mostly relating to pitch distance and plate thickness variation; which, as expected, remain most evident when using a higher order regression model. Montgomery (2012) generally recommends fitting the lowest order polynomial model that sufficiently describes the system. High order models often do not improve the data fitting but only increase the complexity of the model

The HEE functions obtained through $2^{\text {nd }}$ order regression are inherently simpler and show compliance with mainstream literature in regards to hole pitch distance and diameter (Arulanandam et al., 1999; Van Decker et al., 2001; Leon et al., 2007). The effects of absorber plate thickness on HEE, as depicted by the $2^{\text {nd }}$ order model, are consistent with the results reported by Gan et al. (1997) and by Holt et al. (2011) on pressure loss 
variation due to increasing thickness at fixed and relatively small porosity levels. These studies have indicated that the system pressure drop experiences a local minimum with increasing thickness of orifice plates, which explains the correlation between HEE and thickness presented above in Figure 8 . Figure 8 shows how the pressure drop varies as a function of plate thickness at the optimum diameter and pitch values $(D=0.8 \mathrm{~mm}$, $P=7 \mathrm{~mm})$.

The $2^{\text {nd }}$ order model is then taken forward as the most efficient and illustrative, and the higher order models are dismissed due to potential over-fitting, which may lead to misrepresentation of the physical response of the system. The $2^{\text {nd }}$ order regression fit for HEE as a function of the three factors of interest is given by the following correlation:

$\varepsilon=0.45386+0.024778 D-0.04673 P+1.25253 t-0.02419 D^{2}+0.004024 D-$

$0.03931 D t+0.000644 P^{2}+0.012705 P t-0.75648 t^{2}$

The correlation remains valid within the ranges of variability defined before, and reported here for clarity:

- $\quad 0.8 \mathrm{~mm} \leq D<3.2 \mathrm{~mm}$

- $7 \mathrm{~mm} \leq P<23.33 \mathrm{~mm}$

- $\quad 0.7 \mathrm{~mm} \leq \mathrm{t}<1.2 \mathrm{~mm}$

The model shows a Root Mean Squared Error of 3.8\%, and hence is considered sufficient for the purposes of geometry optimisation; the model shows increased accuracy when compared to previous published work (Van Decker et al., 2001)

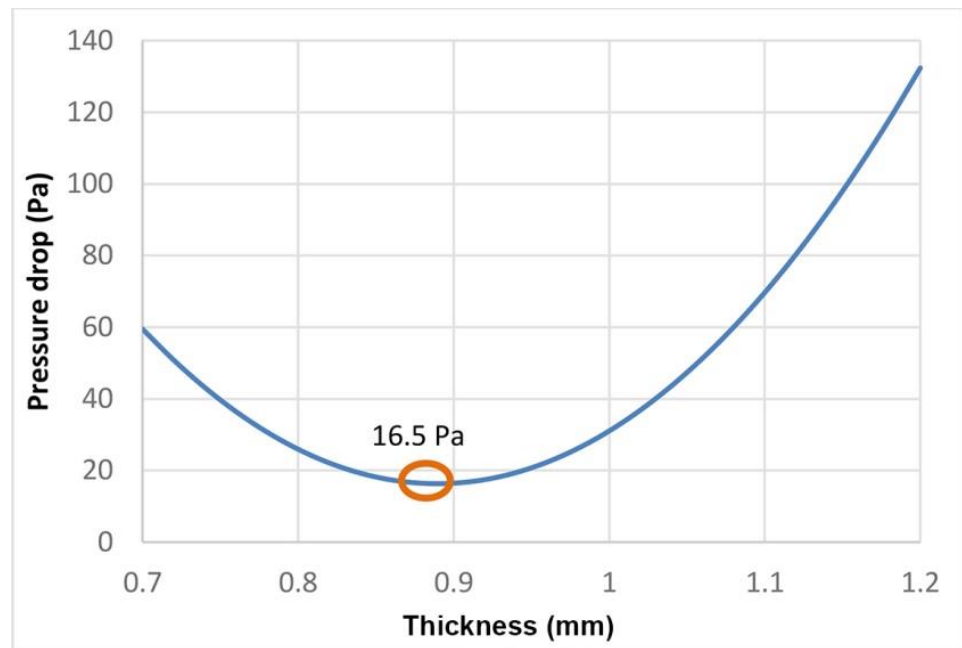

Figure 8. Pressure drop variation across the TSC with $D=0.8 \mathrm{~mm}$ and $P=7 \mathrm{~mm}$ as a function of plate thickness.

The optimised absorber plate geometry, obtained through the application of the selected model, features a perforation diameter of $0.8 \mathrm{~mm}$, pitch of $7 \mathrm{~mm}$ and plate thickness of $0.86 \mathrm{~mm}$. At the operating conditions for which the correlation was developed, this geometry ensures a HEE of about $74 \%$, which corresponds to an increase of about $43 \%$ compared to the original geometry (Figure 4). Compared to recent relevant literature (Tajdaran et al., 2016, Li et al, 2013; Leon et al., 2013), it becomes evident that the variation of HEE, obtained solely by means of geometrical modifications, is similar in magnitude to that associated to typical changes in wind speed, suction ratio and solar radiation - for example, Figure 5 shows that HEE decreases on average by $10 \%$ per $1 \mathrm{~m} / \mathrm{s}$ increase in wind speed, and by $6.5 \%$ per 0.002 increase in suction ratio. In other words, system geometrical optimisation may potentially counteract the adverse effects generated by uncontrollable variation of climatic conditions. Whilst it was established in Tajdaran et al. (2016) that the effect of solar radiation intensity upon HEE is trivial, the model developed here enabled calculating that the temperature rise the system could provide with the optimised geometry is equivalent to an increase in solar radiation intensity by about $122 \mathrm{~W} / \mathrm{m}^{2}$. 


\subsection{Validation}

The geometry optimisation exercise presented in the previous section was carried out using a single set of operating conditions. The present section investigates the applicability of the results to a wider range of operating conditions, with the aim of assessing the effects of potential inter-dependences between geometrical design and environmental variables. A range of simulations have been carried out at different levels of wind speed, suction ratio and solar radiation which have been shown to exert significant influence on the thermal performance of TSC systems (Badache et al., 2012; Van Decker et al., 2001). The details of the new simulations are presented in Table 4. The baseline operating conditions, originally reported in Table 1, are addressed to as to reference conditions. One simulation was performed under reference conditions to validate the consistency between HEE calculated from the CFD model featuring optimal geometry, and HEE predicted using the statistical correlation.

Table 4. Details of the combinations of operating conditions used to validate the optimised geometry

\begin{tabular}{|c|c|c|c|c|}
\hline Case No. & Comment & Wind speed $(\mathrm{m} / \mathrm{s})$ & Suction ratio (-) & Solar radiation $(\mathrm{W} / \mathrm{m} 2)$ \\
\hline 1 & Reference Condition & \multirow{5}{*}{5} & \multirow{3}{*}{0.008} & 600 \\
\hline 2 & Solar radiation variation 01 & & & 450 \\
\hline 3 & Solar radiation variation 02 & & & 705 \\
\hline 4 & Suction ratio variation 01 & & 0.006 & \multirow{4}{*}{600} \\
\hline 5 & Suction ratio variation 02 & & 0.01 & \\
\hline 6 & Wind speed variation 01 & 3 & \multirow{2}{*}{0.008} & \\
\hline 7 & Wind speed variation 02 & 7 & & \\
\hline
\end{tabular}

All the validation results are summarised in Figure 9. The 'Reference Conditions' simulation shows a level of HEE which is roughly $46 \%$ higher than that calculated using the standard geometry. This is three point percent greater than the level predicted using the statistical model, which is acceptable and within expected uncertainty. The results for different environmental variables also indicate a large, generalised improvement in HEE for the optimised design, with an average growth of about $43 \%$. In other words, regardless of the combination of external conditions, the optimised absorber plate geometry would deliver $43 \%$ hotter air temperature on average for a constant absorber surface temperature. Figure 9 also shows that the advantage of using an improved geometry grows as environmental conditions of wind speed and suction ratio become more demanding. Importantly, due to the reduction in thickness, the improvement in performance is gained using $28 \%$ less material (by volume), which holds a clear positive impact for manufacturers and users alike.

A comparison has also been made between temperature and pressure distributions within the TSC plenum for the default (Tajdaran et al., 2015) and the optimised geometries (Figure 10). Since the system is relatively long $(0.14 \mathrm{~m} \times 1.76 \mathrm{~m})$, it has been presented in two parts (top and bottom) for clarity. Both distributions show a clear gradient moving from the bottom to the top side, due to the blocked/solid bottom compounded with the presence of an air fan at the top outlet side. The optimised geometry delivers globally a higher grade of air temperature which supports the predicted improvement in thermal performance. As suggested by the pressure distributions and average levels from Figure 8, this is due to the higher porosity of the optimised geometry $(0.01$ compared to 0.0044 for the default geometry) leading to a significantly lower inlet-to-outlet pressure drop. All in all, the new TSC design is characterised by lower heat losses and would require less airflow work to deliver the heated air into the outlet. 

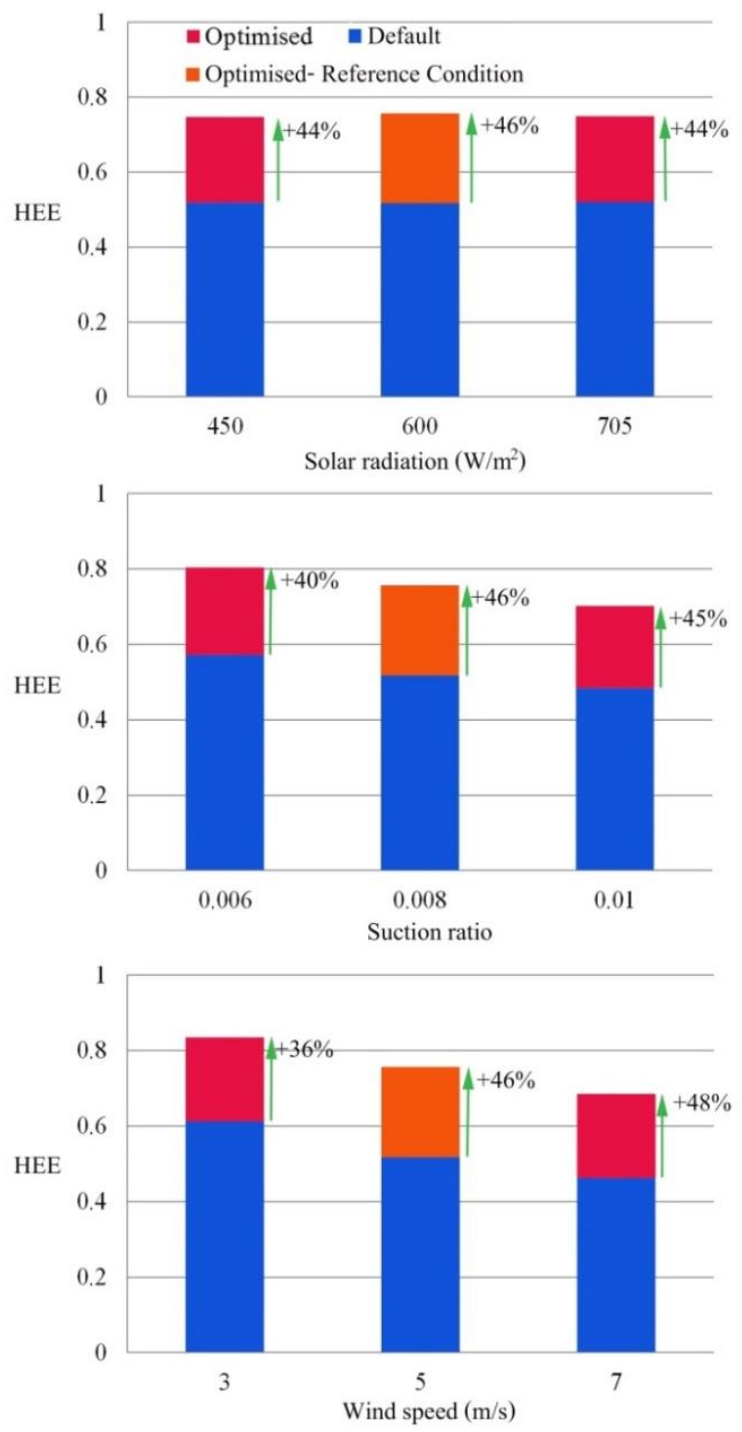

Figure 9. A comparison of effectiveness of default and optimised TSC geometries for a range of operating conditions.

This optimisation study can be taken further in future to integrate the effect of the collectors' coating properties and the different materials' thermal properties (e.g. thermal conductivity) exploring an improved efficiency for the TSCs. Use of thermal storage together with the fully optimised TSC systems can also be the subject of future research in particular during the day time when there is excess heat available as was demonstrated in Tajdaran et al. (2016). 
Top
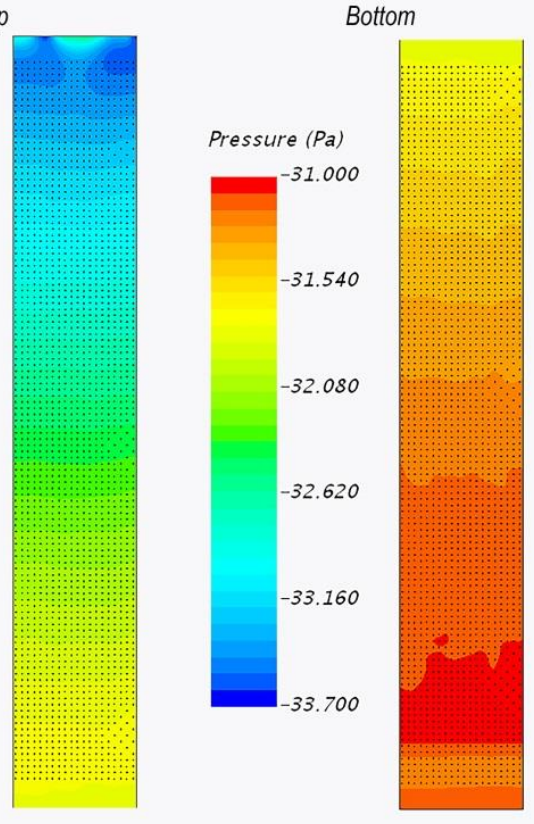

Top

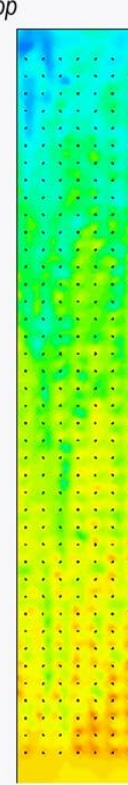

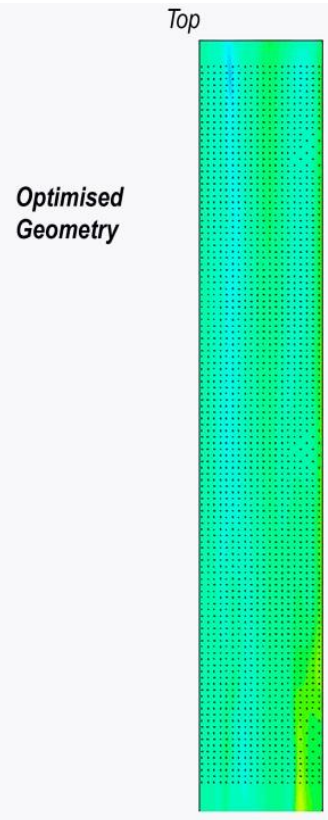

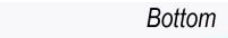

Temperature (C)

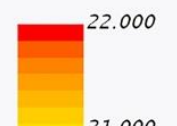

21.000

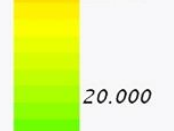

20.000
19.000

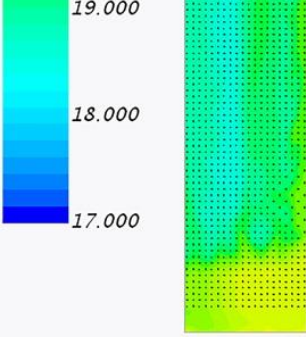

Top

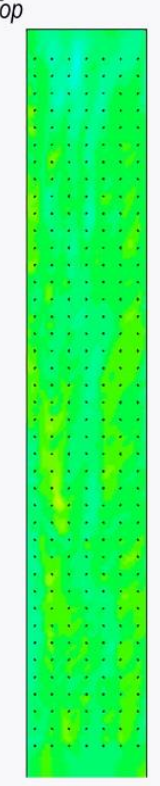

Bottom

Temperature (C)

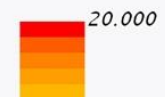

19.000

Default

Geometry
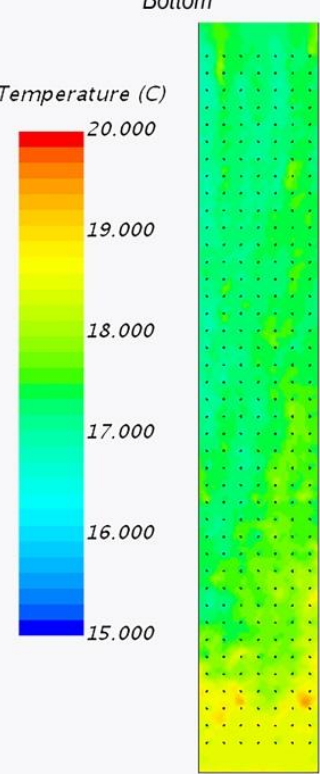

Figure 10. Comparison of air temperature and pressure distribution taken place within the plenum for default and optimised geometry captured from the front view.

\section{Conclusion}

In line with the international research effort towards renewable energy resources technologies as alternatives for conventional fuel based heating systems, TSCs have been a subject of a great deal of research to provide a better understanding of the key aspects of the underlying physics and an improved performance of the systems. This work uses a formerly developed and validated CFD model to optimise the geometry of the absorber plate. 
Such optimisation is necessary to enhance the performance of TSCs in order to generate a relatively higher grade heat.

The model has been used to perform experiments providing a sufficient number of results for optimisation analysis. The aim has been to introduce an optimised combination of absorber plate geometrical variables which maximises the heat exchange effectiveness of the system. The Design of Experiments (DoE) technique has been employed to plan a series of combinations for the experiments.

The key findings of the study are:

- 42 experimental setups with different combination of geometrical variables, under a fixed climatic and operating condition, have been performed and the responses (HEE) have been fit to a second order polynomial model as a function of thickness, diameter and pitch. The predictive model is generated for $0.8 \mathrm{~mm} \leq D<3.2 \mathrm{~mm}, 7 \mathrm{~mm} \leq P<23.33 \mathrm{~mm}, 7 \mathrm{~mm} \leq t<1.2 \mathrm{~mm}$.

- The optimum geometry configuration has been found to be: $\mathrm{D}=0.8 \mathrm{~mm}, \mathrm{P}=7 \mathrm{~mm}, \mathrm{t}=0.866 \mathrm{~mm}$ which is predicted to deliver a HEE of 0.739 . This is about $43 \%$ increase in HEE compared to the default geometry. This growth has been validated against the CFD model incorporating the optimum configuration. This level of increase in HEE by optimised geometry is highly comparable with the variation HEE against wind speed, suction ratio and solar radiation. Effectiveness decreases on average by $10 \%$ per $1 \mathrm{~m} / \mathrm{s}$ of wind speed and $6.5 \%$ per 0.002 suction ratio, respectively. In other words, just by optimising the geometry, the system can potentially benefit from resisting against such phenomena. The temperature rise that the system could provide with the optimised geometry is equivalent to increasing solar radiation intensity by about $122 \mathrm{~W} / \mathrm{m}^{2}$.

- Whilst the HEE correlation has been generated for one single operating condition its applicability to variant climatic conditions has been verified against different solar radiation, suction ratio and wind speed levels. Irrespective of the combination of different conditions, the optimised absorber plate geometry has been able to show an average enhancement of about $43 \%$ across the tested conditions.

- Both the pressure drop across the system and total pressure distribution within the plenum have shown a significant reduction with the optimum geometry compared to the default one. The optimised geometry has also shown a higher level of temperature distribution in the plenum. In other words, in spite of the reduced surface area of the optimised configuration due to its higher porosity $(0.010$ as opposed to 0.0044), the improved thermal performance indicates that the system loses less heat compared to TSCs with larger pitch and perforation diameter. Hence the optimised geometry is able to both increase the heat gain and facilitate a lower pressure drop across the system.

The impact of porosity together with the thickness of the absorber plate on the airflow pressure distribution and subsequently the thermal performance of TSCs has been illustrated in this work. As a consequence of the optimisation study the system is able to perform $43 \%$ better using $28 \%$ less material which is a significant impact for the TSC manufacturers and users, in particular in countries with less available solar radiation such as the UK. Such optimisation analysis can be morphed to other applications with careful consideration of corresponding limitations.

Further research can focus on evaluation of the performance integrating thermal properties of the absorber plate to the geometry optimisation. Enhancement strategies can also include investigation about modified profiles of absorber plates coupled with other technologies converting TSCs to a cheap and low maintenance heating system with wider applications. 


\section{References}

Athienitis, A.K., Bambara, J., O’Neill, B., Faille, J.( 2011). A prototype photovoltaic/thermal system integrated with transpired collector. Solar Energy 85, pp. 139-153.

Abulkhair, H.,Collins, M. (2010). Investigation of wind heat loss from unglazed transpired solar collectors with corrugation. 5th Annual International Green Energy Conference, pp. 1-3.

Arulanandam, S.J., Hollands, K.G.T., Brundrett, E. (1999). A CFD heat transfer analysis of the transpired solar collector under no-wind conditions. Solar Energy, 67 (1), pp. 93-100.

Badache, M., Halle', S., Rousse, D. (2012). A full $3^{4}$ factorial experimental design for efficiency optimization of an unglazed transpired solar collector prototype. Solar Energy, 86, pp. 2802-2810.

Badache, M., Rousse, D., Halle', S., Quesada, G. (2013). Experimental and numerical simulation of a twodimensional unglazed transpired solar air collector. Solar Energy, 93, pp. 209-219.

Biona, M., Culaba, A., Serafica, E., Mundo DR., (2005). Performance curve generation of an unglazed transpired collector for solar drying applications. In: Proceedings of World Renewable Energy Regional Conference.

Collins, M., Abulkhair, H., (2014). An evaluation of heat transfer and effectiveness for unglazed transpired solar air heaters. Solar Energy, 99, pp. 231-245.

Dymond, C., Kutscher, C. (1997). Development of a flow distribution and design model for transpired solar collectors. Solar Energy, 60(5), pp. 291-300.

Fleck, B., Meier, R., Matovic, M. (2002). A field study of the wind effects on the performance of an unglazed transpired solar collector. Solar Energy, 2002, 73(3), pp. 209-16.

Gan, G. and Riffat, S.B. (1997). Pressure loss characteristics of orifice and perforated plates. Experimental thermal and fluid science, 14(2), pp.160-165.

Garud, S., Karimi, I. and Kraft, M. (2017). Design of computer experiments: A review. Computers \& Chemical Engineering, 106, pp.71-95.

Gawlik, K.M., Christensen C, Kutscher C. (2002). Wind Heat Loss From Corrugated, Transpired Solar Collectors. Journal of Solar Energy Engineering, 124 (3), pp.256-261.

Golneshan, A., (1994). Forced convection heat transfer from low porosity slotted transpired plates. Ph. D. Thesis, Department of Mechanical Engineering, University of Waterloo.

Gunnewiek, L., Brundrett, E., Hollands, K., (1996). Flow distribution in unglazed transpired plate solar air heaters of large area. Solar Energy, 58, pp.227-237.

Gunnewiek, L., Hollands, K., Brundrett E., (2002). Effect of wind on flow distribution in unglazed transpired plate collectors. Solar Energy, 72, pp.317-325.

Hall, R., Kendrick, C. and Lawson, R. (2014). Development of a cassette-panel transpired solar collector. Proceedings of the Institution of Civil Engineers - Energy, 167(1), pp.32-41.

Hall, R. and Blower, J. (2016). Low-emissivity Transpired solar collectors. Energy Procedia, 91, pp. 56-63.

Hollick. J.C., (1994). Unglazed solar wall air heaters. Renewable Energy, 5(1-4), pp145-421. 
Kutscher, C.F., (1992). An investigation of heat transfer for air flow through low porosity perforated plates. Ph.D. Thesis, Department of Mechanical Engineering, University of Colorado at Boulder, Colorado, USA.

Holt, G.J., Maynes, D. and Blotter, J. (2011). Cavitation at sharp edge multi-hole baffle plates. In ASME 2011 International Mechanical Engineering Congress and Exposition, pp. 401-410.

Leon, M., Kumar S., 2007. Mathematical modeling and thermal performance analysis of unglazed transpired solar collectors. Solar Energy 81, 62-75.

Li, S., Karava, P., Savory, E., Lin, W. (2013). Airflow and thermal analysis of flat and corrugated unglazed transpired solar collectors. Solar Energy, 91, pp. 297-315.

MATLAB \& SIMULINK ${ }^{\mathrm{TM}}$ R2017, (2017), CAGE User's Guide, The MathWorks Inc., Natick, Massachusetts.

Montgomery, D. C. (2012). Design and analysis of experiments. New York: Wiley.

Schlichting, H. (1979) Boundary-layer theory. New York: McGraw-Hill.

Tajdaran, S., Bonatesta, F., Ogden, R. and Kendrick, C. (2015). Use of CFD modelling for transpired solar collectors and associated characterization of multi-scale airflow and heat transfer mechanisms. Energy Procedia, 78 , pp.2238-2243.

Tajdaran, S., Bonatesta, F., Ogden, R. and Kendrick, C. (2016). CFD modelling of transpired solar collectors and characterisation of multi-scale airflow and heat transfer mechanisms. Solar Energy, 131, pp.149-164.

Van Decker, G.W.E., Hollands, K.G.T., Brunger, A.P., (2001). Heat-exchange relations for unglazed transpired solar collectors with circular holes on a square or triangular pitch. Solar Energy 71, pp.33-45.

Wang, X., Lei, B., Haiquan, B., Tao, T. (2017). A simplified method for evaluating thermal performance of unglazed transpired solar collectors under steady state. Applied Thermal Engineering, pp. 185-192. 